\title{
Blocos carnavalescos: culturas populares, culturas híbridas no carnaval de rua do Rio de Janeiro
}

\author{
Bloques carnavalescos: culturas populares, culturas hibridas \\ en el carnaval de calle de Rio de Janeiro
}

\section{Carnival street bands (blocos): popular cultures, hybrid cultures of street carnival in Rio de Janeiro}

\author{
Rita Fernandes'
}

Palavras chave:

Carnaval de rua

Blocos carnavalescos

Cultura popular

Culturas híbridas

\section{Resumo:}

Este artigo traz uma reflexão sobre o Carnaval de Rua do Rio no século 21, especialmente diante do fenômeno da multiplicidade de agremiações e diversidade de formatos, matizes e intenções, e as disputas de significados e de representatividade em que se colocam os agentes envolvidos - blocos, associações e poder público -, que buscam ancorar-se em conceitos como "cultura popular", "tradição" e "identidade" para justificar seus espaços de legitimidade. Para conduzir essa análise e demonstrar as dificuldades de conceituações nesses campos, é proposto um diálogo entre as ideias dos historiadores Marta Abreu, com uma análise de seu texto "Cultura Popular: um conceito e várias histórias", e de Nestor Canclini, com seu livro "Culturas Híbridas". 


\section{Resumen:}

Este artículo presenta una reflexión sobre el Carnaval de Calle de Rio de Janeiro en el siglo XXI, especialmente a la luz del fenómeno de la multiplicidad de agremiaciones y diversidad de formatos, matices e intenciones, y a las disputas de significado y representatividad en que se colocan los agentes envueltos - bloques, asociaciones y poder público - que buscan afirmarse en conceptos tales como "cultura popular" y "tradición" para justificar sus espacios de legitimidad. Para llevar a cabo este análisis y demostrar las dificultades de conceptualizaciones en estos campos, se propone un diálogo entre las ideas de los historiadores Marta Abreu, expuestas en el texto "Cultura Popular: un concepto y una gran cantidad de historias", y las de Néstor Canclini, presentes en su libro "culturas híbridas".

\section{Palabras clave:}

Carnaval de calle

Bloques carnavalescos

Cultura Popular

Culturas híbridas

\section{Keywords:}

\author{
Street Carnival \\ Carnival street bands \\ (blocos) \\ Popular culture \\ Hybrid culture
}

\section{Abstract:}

This article presents a reflection on Rio de Janeiro's Street Carnival in the 21st century, especially in light of the phenomenon of the multiplicity of associations and diversity of formats, shades and intentions, as well as disputes over meanings and representativeness as presented by those involved - street bands (known as 'blocos'), associations and public authorities - that seek anchoring in concepts such as "popular culture", "tradition" and "identity" to justify their spaces of legitimacy. To conduct this analysis and demonstrate the difficulties of defining concepts in these fields, a dialogue is proposed between the ideas of historians Marta Abreu, with an analysis of her text "Popular Culture: a concept and various stories" and those of Nestor Canclini, in his book "HybridCultures". 


\section{Blocos carnavalescos: culturas populares, culturas híbridas no carnaval de rua do Rio de Janeiro}

\section{O texto "Cultura Popular, um concei-} to e várias histórias", de Martha Abreu, traz uma interessante reflexão sobre as dificuldades no uso do termo "cultura popular" que pode ser estendida ao Carnaval de rua do Rio, na sua versão atual, com mais de 500 blocos espalhados pela cidade, com diferentes formatos, narrativas, organizações e intenções. A cidade vive uma verdadeira febre carnavalesca, a exemplo do que aconteceu no início do século 20, quando também se viu tomada por grupos de foliões organizados nas mais diversas formas, com os corsos, os cordões, os ranchos e ainda a presença de algumas sociedades carnavalescas. (BEI, 2007; FERREIRA, 2004).

Houve um crescimento fenomenal do número de agremiações e de foliões na última década - 504 blocos autorizados pela Empresa de Turismo do Município do Rio de Janeiro - Riotur e mais de 5 milhões de pessoas nas ruas do Rio, em 2016 - e, em paralelo, um crescente interesse da mídia sobre o tema. Com essa grande onda que - Carnaval de rua se tornou, veio também a disputa por protagonismos e de significados por parte dos vários agentes envolvidos, como os grupos organizadores de blocos de rua, as ligas, a mídia e o poder público.

Com o poder de movimentar mais de $R \$ 2$ bilhões de reais na cidade, oriundos dos gastos com hospedagem, bares e restaurantes e outros serviços", num espaço de tempo de praticamente 45 dias, o fato é que a atividade começou a interessar muito ao mercado a partir dos anos 2000 - pela visibilidade, abrangência e ressonância que os blocos desfrutam na sociedade contemporânea, não mais apenas no Rio, que serviu de modelo para ou- tras cidades, mas especialmente aí. E a disputa entre os grupos passou a se dar em torno de questões como legitimidade, autenticidade e tradição. Entre alguns dos motivos dessa disputa, a corrida pelas verbas de patrocínio disponíveis no mercado para este segmento.

Há, entre os diferentes agentes, algumas tentativas de classificações, como a que gira em torno das representações de uma "verdadeira cultura popular", por exemplo, como se isso fosse possível ou necessário para balizar quem tem mais ou menos direitos como em relação às disputas de uso do espaço público (quem pode ou não ocupar qual rua, qual o lugar de cada um); quem está nas representações da "tradição" do Carnaval; quem deve ter direito ao dinheiro público e por quê. "Cultura popular é um dos conceitos mais controvertidos que conheço", escreve na abertura de seu texto Abreu (2003, p. 83). Compartilhando com Bourdieu (1996) o quanto é complexo transitarmos sobre a noção do que é "popular"

Se, a despeito de suas incoerências e incertezas, e também graças a elas, as noções pertencentes à família do "popular" podem prestar muitos serviços, e até no discurso erudito, é porque elas estão profundamente encerradas na rede de representações confusas que os sujeitos sociais engendram, para as necessidades do conhecimento corriqueiro do mundo social e cuja lógica é a da razão mítica. (BOURDIEU, 1996, p. 18)

Na questão do dinheiro público dá-se uma das principais disputas em torno dos significados. Mesmo que houvesse por parte da gestão municipal atual alguma disposição na criação de editais e de linhas de fomento para os blocos"', umas das maiores dificuldades seria estabelecer categorias e enquadramentos que conseguissem classificar, de forma equânime, as mais de 500 agremiações, entre outros problemas apontados por Frydberg. 
Blocos que concorrem aos editais de incentivo fiscal na área da cultura, geralmente não tem suas propostas contempladas, pois são considerados inaptos a participarem de tais editais. Essas decisões não reconhecem os blocos de carnaval como passíveis de incentivos do poder público, os associam aos acontecimentos mercadológicos que visam o lucro. Podemos visualizar, assim, a dificuldade do poder público, nas suas mais variadas instâncias, em reconhecer o carnaval de rua como expressão da cultura popular possível de ser valorizada, incentivada, reconhecida como manifestação artística e cultural e, desta forma, financiada pelos editais que tem como objetivo promover a cultura nacional através da legitimação do Estado da sua importância. (FRYDBERG, 2014, p.11)

No Rio, hoje, há blocos de diferentes origens, tamanhos, matizes e formações. Há grupos como Monobloco, Bloco da Preta e Sargento Pimenta, com suas estruturas profissionais que, para setores mais críticos, reproduzem com seu modelo uma faceta da comercialização ou da mercantilização do Carnaval de rua carioca.

Há outros, chamados de "tradicionais" tanto pela imprensa quanto pelos próprios agentes $^{\mathrm{IV}}$, como o Cordão da Bola Preta, o Suvaco do Cristo e o Simpatia é Quase Amor, para citar alguns, e que fazem do discurso da "autenticidade" sua bandeira. E há ainda outros, que trabaIham no campo da "resistência", e que se autodeclaram os representantes da cultura popular, como o Boi Tolo e outros da Desliga. Tomando o termo tradicional para um breve exercício, por exemplo, termo tão complexo em si mesmo, como narra Abreu em seu texto; que critérios definiriam o que é 'tradicional' no Carnaval de rua, se desde fins do século 19 já se passou por tantas modificações e formas de organização?
Sobre disputa de representação e de legitimidade, usando o termo cultura popular, por exemplo, um dos representantes do bloco Boi Tolo e da Desliga dos Blocos do Riov, Diogo Eduardo, define o que pensa sobre o assunto em entrevista a um blog: ${ }^{\mathrm{V}}$

O carnaval é uma manifestação de cultura popular e cultura popular não é feita nem por vanguarda nem por meia dúzia de intelectuais. É feita pela massa que vai para a rua e toma um espaço que é dela. A praça é do povo, então ela tem que ser tomada. O problema é como o mercado e o Estado percebem isso. Esse é o grande $x$ da questão.

Este artigo se propõe a pensar como é difícil, talvez mesmo impossível, estabelecer limites classificatórios para o Carnaval de rua carioca, em um cenário de tanta diversidade. Peter Burke já sinalizava em seu livro Cultura Popular na Idade Moderna (2010) que o termo "cultura popular" dá uma falsa impressão de homogeneidade e que seria melhor usá-lo no plural. Já Abreu (2003) começa seu texto destacando que cultura popular é um dos conceitos mais controversos que conhece, e o quanto tem sido utilizado com objetivos e em contextos tão diversos desde o século 18, quase sempre carregados de juízos de valor, idealizações, homogeneizações e disputas teóricas e políticas.

Essa discussão esteve na pauta dos seminários "Desenrolando a Serpentina" realizados pela SebastianaVII em 2014 e em 2015, onde o debate esteve centrado no fato de que o carnaval dos blocos, no Rio, tem sido tratado apenas dentro do campo do Turismo e longe do da Cultura, numa lógica das vantagens econômicas da atividade para a cidade, desde que o prefeito Eduardo Paes assumiu a prefeitura e começou a normatizar a atividade VIII. Por estar no quadro de responsabilidades desta secretaria, que se atém muito mais aos aspectos operacionais e econô- 
micos da festa, o Carnaval de rua não tem contado com um outro olhar que aborde a sua representatividade cultural, sob outras óticas, para a cidade. Nesse impasse, vai crescendo geometricamente o número de agremiações ano a ano, sem que haja, de fato, uma política pública que beneficie os blocos. Entre contradições da atuação municipal, pautada por diretrizes de uma política neoliberal, a mesma prefeitura que negocia o direito de uso da marca "Carnaval de rua" a empresas, como um produto, se utiliza da imagem de uma "legítima manifestação cultural popular espontânea" para reforçar a identidade carioca atrelada ao discurso institucional de legitimação da "vocação da cidade". Em entrevista, o subsecretário especial da Empresa de Turismo do Município do Rio de Janeiro Riotur no ano de 2013, Pedro Guimarães, declarou: "O carnaval de rua é uma manifestação cultural que traduz a identidade da cidade, uma manifestação cultural espontânea das pessoas, e o carioca tem orgulho desse estilo de vida, traduzido por essa maneira de brincar o carnaval". IX

O texto de Martha Abreu joga um pouco de luz nesse debate ao discorrer sobre as várias interpretações da cultura popular, desde o pensamento dos folcloristas, passando pelos sociólogos da Universidade de São Paulo e pelos marxistas, até chegar ao pensamento mais atual de Nestor Canclini, com seu conceito de "culturas híbridas"x. Para uma interpretação dos fatos mais recentes, a análise do antropólogo argentino em muito nos pode ajudar. Mas, para o maior aprofundamento desse tópico, dedicaremos a segunda parte deste artigo, no qual faremos considerações mais específicas. Nesse momento, convém iniciarmos esta reflexão reconhecendo que cultura popular é mesmo um conceito muito difícil de ser definido, cheio de contradições, e que envolve jogos de interesses políticos, que o cercam ao longo dos tempos, como demonstra Abreu (2003).

\section{Culturas populares}

Será na própria história do conceito, criado no séc. XVIII, e nos seus diversos significados, que a autora irá buscar a chave para explicar o conjunto de dificuldades que lhe são atribuídas quando tentamos interpretá-lo. Folclore? Tradição? Aquilo que é genuíno do povo, sendo este entendido como o conjunto de pessoas de classes sociais mais baixas e menos desprovidas? Contraponto ao conceito do que é erudito? Aquilo que é de consumo da grande massa, e que está em vantagens de mercado sobre outros ativos culturais?

Seguindo a história, vamos encontrar múltiplas respostas em diferentes períodos para a pergunta 'O que é cultura popular?'. $E$ veremos que, seja qual for o sentido escolhido, a resposta sempre vem carregada de juízos de valor, de enquadramentos ou de homogeneizações, de disputas, de embates entre oposições como tradicional-moderno, urbano-rural etc. Martha Abreu cita Roger Chartier, historiador contemporâneo, para mostrar ser "impossível saber o que é genuinamente do povo, pela dificuldade ou mesmo impossibilidade de se precisar a origem social das manifestações culturais, em função da histórica relação e do intercâmbio cultural entre os mundos sociais, em qualquer período da história" (CHARTIER, 1995).

Cabe lembrar a afirmação que a autora faz de que cultura popular não é um conceito que possa ser definido "a priori, como uma fórmula imutável e limitante". Parece oportuna essa possibilidade de encararmos a cultura popular muito mais como uma perspectiva, uma espécie de ponto de vista em relação ao que um determinado grupo social produz como cultura. Traz uma visão mais importante para se criar possibilidades de se evidenciar diferenças e colocar em perspectiva realidades culturais multifacetadas. Afinal, esse parece ser o caráter da cultura popular na modernidade. $E$ podemos nos transportar aqui 
novamente ao universo do Carnaval de rua carioca, com sua pluralidade e as inúmeras possibilidades de significados, de formas de organização e agentes diversos.

O desenvolvimento do termo cultura popular no Brasil sempre esteve ligado à construção de um pensamento sobre identidade cultural, em qualquer dos períodos que possam ser estudados desde o século 19. A cultura popular foi tida como folclore por muito tempo por alguns grupos, entendendo folclore como um conjunto de tradições culturais de um país ou de uma determinada região, aquilo que valoriza o tradicional e tudo o que o permeia a autenticidade da cultura popular era considerada fundamental para legitimar a verdadeira singularidade nacional.

Assim como em outros países da América Latina, o folclore no país serviu para a formação dos estados-nação, consolidando identidades nacionais. Tanto que, desde Silvio Romero, intelectuais apontam a cultura popular, com ênfase na música, como expressão da nossa identidade desde o fim do século XIX. Essa abordagem vai ganhar força de fato em todo o território nacional a partir da década de 1930, "quando consagrou-se a estreita união entre a identidade nacional, a miscigenação e a positiva e rica cultura popular nacional", como aponta Abreu. E, nos marcos desse movimento, destacam-se a obra do sociólogo Gilberto Freyre, com seu Casa Grande \& Senzala, publicado em 1933, e as grandes ações do governo de Vargas, que vai se apropriar da cultura popular levando-a para a tutela do Estado, como fez com o samba e as escolas de samba, por exemplo. É nesse movimento que surge o sentido de autenticidade e uma direta vinculação ao conceito de tradição naquilo que é considerado popular. $E$ aqui o carnaval ganha a chancela de cultura popular como símbolo de legitimação de uma identidade nacional. As escolas de samba, que são a expressão mais importante do carnaval desta época, vão representar esse papel. A historiadora Rachel Soihet, em seu livro "A subversão pelo riso", mostra que esse movimento, no entanto, não se deu de forma unilateral, como pregam alguns autores, tendo como agentes o próprio governo e os líderes populares:

Vargas, a partir de sua ascensão, vale-se da música popular e das agremiações carnavalescas como veículo para a integração dos populares ao seu projeto de construção da nacionalidade. Paralelamente, toma vulto o esforço de líderes populares, para afirmar sua participação no sistema, garantindo a presença reconhecida das manifestações nas ruas da cidade. Dessa coincidência de interesses resulta o predomínio popular no Carnaval, tornando-se o samba sua música característica. (SOIHET, 2003, p. 121)

Mas, voltando aos folcloristas, se estes valorizavam o caráter tradicional e autêntico, como traços de uma identidade cultural e étnica, idealizando um autêntico "povo rural", como se este estivesse fora de um sistema de dominação de classes, os sociólogos da USP nas décadas de 1950 e 1960, liderados por Florestan Fernandes, vão deslocar a reflexão para um contexto voltado à modernização e às questões relacionadas às desigualdades sociais. Os folcloristas vão sofrer inúmeras críticas da academia, por defenderem uma prática tida como não-científica e por estarem do lado das forças conservadoras do governo e por não considerarem a cultura como um embate entre os extratos subalternos e as classes dominantes. Marta Abreu afirma que desse movimento crítico e feroz resulta a repercussão negativa que o termo folclore acabou adquirindo, chegando mesmo a conotações como "anedótico" e "ridículo".

Para os sociólogos ligados à USP, não se poderia pensar mais em "integra- 
ção cultural", como defendiam os folcloristas, já que seria necessário considerar as mudanças sociais eminentes de uma sociedade cheia de conflitos, em que a cultura popular autêntica não teria como ser produzida pelo povo, pois este se tornara o proletariado. Ganha espaço no discurso dos acadêmicos as discussões sobre desigualdades de classe e o debate sobre cultura popular transfere-se para o campo da alienação e de uma não-consciência, consolidando visões muitas vezes preconceituosas sobre o que é cultura popular: "cultura fragmentada, conservadora, presa às tradições, obstáculo às mudanças sociais", entre outros adjetivos.

Dessa abordagem também vão participar, a partir da década de 1970, os intelectuais marxistas influenciados pelo pensamento de Gramsci, em que "as culturas subalternas, em sua perspectiva, seriam o resultado da distribuição desigual dos bens econômicos e culturais, ao mesmo tempo em que poderiam oferecer uma forma de oposição à cultura hegemônica, dos setores dominantes" (ABREU, 2003, p. 88). E, do pensamento marxista, surgem as bases de reflexão sobre o caráter de resistência dos setores populares, oprimidos em suas condições de vida e cultura.

Se o conceito da cultura nas sociedades civilizadas foi sendo definido a princípio no campo de disciplinas como o folclore, a antropologia social e a sociologia, só na década de 1970 o seu estudo passa a interessar à historiografia. Carlo Ginzburg (apud ABREU, 2003, p. 89) aprofundou a discussão de questões que foram cruciais para os historiadores, como a relação entre a cultura das classes subalternas (termo cunhado por Gramsci) e a das classes dominantes. Ginzburg põe em debate até que ponto existe subordinação entre as classes e busca entender a circularidade da cultura ${ }^{X I}$ (SOIHET, 1998, p. 16). Essa discussão proposta por Ginzburg foi parte de um movimento mui- to mais amplo de historiadores ligados à história social nessa década, que resgata a perspectiva da cultura na história e também da história vista a partir do povo. Estão também envolvidos na discussão de cultura popular e se tornam autores referenciais Peter Burke, Mikhail Bakhtin, Robert Darnton e E. P. Thompson.

Burke (apud ABREU, 2003, p. 90) foi um dos primeiros autores a falar da cultura popular de forma global e é responsável pelo termo "biculturalidade", para mostrar que os representantes da elite conheciam e participavam da cultura popular, sem abandonar a sua. $O$ historiador chamou atenção para "a possibilidade de significados diferentes, quando práticas culturais eram compartilhadas". $\mathrm{E}$, ao voltarmos atrás nas investigações sobre o Carnaval, veremos, dentro dessa perspectiva de Burke, como o conceito se aplica no Brasil aos cordões, às grandes sociedades e depois aos ranchos, no período entre o final do século 19 e meados do século 20. Assim escreveu Soihet, destacando a configuração dos ranchos e principalmente a sua musicalidade:

Temas e artistas eruditos estavam presentes nessas agremiações; e suas melodias inspiravam compositores dos segmentos médios a produzir músicas de idêntico estilo. Configurava-se a circularidade cultural, fruto de estratégias e da resistência dos populares. (SOIHET, 1998, p. 95)

Em contraposição à Burke, E. P. Thompson (apud ABREU, 2003, p. 91) destaca que a discussão sobre cultura popular deve ser inserida no movimento das classes trabalhadoras em defesa de seus costumes e face às pressões que sofriam dos diferentes agentes de dominação. $O$ historiador criticou muito a visão da tradição, entendida como sobrevivência e manutenção de um passado, destacando que a tradição deveria ser "compreendida, em 
termos políticos, como um local de disputas e conflitos entre interesses opostos". Abreu chama a atenção para este ponto como a maior contribuição de Thompson nos estudos da cultura popular:

O autor recomenda muita atenção para os perigos de se trabalhar com uma ideia de cultura popular como uma perspectiva ultraconsensual e simplificadora, que determinadas definições antropológicas podem sugerir, como por exemplo a que foi utilizada por Peter Burke no trabalho de 1978 [...]. Nas suas reflexões, cultura é um conjunto de diferentes recursos, em que há sempre uma troca entre o escrito e oral, o dominante e o subordinado, a aldeia e a metrópole. É uma arena de elementos conflitivos localizados dentro de específicas relações sociais e de poder, de exploração e resistência à exploração. (ABREU, 2003. p. 91-92)

Confirmando o caráter contraditório e ao mesmo tempo político do conceito, a partir da década de 1960, no Brasil, a cultura popular passa a fazer parte dos discursos dos movimentos de esquerda e assume o sentido de resistência de classe ou, inversamente, da necessidade de tomada de consciência das classes oprimidas. E vai parar nos novos movimentos culturais que querem expressar as posições da esquerda brasileira que começa a ser silenciada pela ditadura militar.

Há depois uma outra tendência, mais atual, relacionada aos pensadores das indústrias culturais e da comunicação de massa, que associa cultura popular ao tamanho do público consumidor dos ativos culturais. Popular seria aquilo que atinge um grande público, que tem maior consumo entre os diferentes "produtos" ofertados no mercado. Por essa visão, poderíamos considerar o Carnaval de rua do Rio um grande exemplo da cultura popular - afinal, são mais de cinco milhões de pessoas, segundo dados da Secretaria Municipal de Turismo.

Diante de tantas possibilidades exploradas até aqui, não há dúvida de que a compreensão da relação entre culturas tradicionais e populares e as pressões impostas pela modernidade são um marco na compreensão do conceito em si, em qualquer dos períodos que se analise. É a essa maleabilidade de compreensão do que se trata a cultura popular que Martha Abreu se refere quando afirma ser um conceito difícil de definir e controverso por natureza, pois se presta a um e a outro lado do pensamento político, histórico e social. Mas proponho avançarmos nesta reflexão por novas abordagens, as quais considero mais pertinentes à análise do fenômeno atual dos blocos de rua, dentro do pensamento do antropólogo Nestor Canclini, que discorre sobre o conceito de culturas híbridas.

\section{Culturas híbridas}

Dialogando com o texto de Martha Abreu, a classificação de cultura popular proposta por Canclini, em seu livro Culturas Híbridas, parece a mais pertinente para o estudo do Carnaval de rua do Rio. O autor propõe que "as culturas populares conseguem ser, atualmente, prósperas e ao mesmo tempo híbridas", e "o desenvolvimento moderno não teria suprimido as culturas populares". Em sua concepção, as culturas tradicionais desenvolveram-se e modificaram-se por diferentes motivos, mas a produção cultural dos setores populares se manteve independe de qualquer fator, sejam por razões econômicas ou culturais. Como afirma Abreu, "o importante, diferentemente da perspectiva folclorista, não seria buscar o que não muda: mas por que muda, como muda e interage com a modernidade".

Essa perspectiva se adequa bastante aos blocos de rua do carnaval do Rio na contemporaneidade, já que nenhuma 
classificação anterior pode ser capaz de descrever a pluralidade do que acontece no período momesco na cidade, com seus atores e agentes. Hoje, não parece ser possível fechar uma classificação única sobre o que é um bloco carnavalesco, sem considerar a multiplicidade de formas possíveis dentro desse universo. Considerando-se características "tradicionais" do carnaval de rua antes dos anos 1980, bloco poderia ser definido como um conjunto de pessoas desfilando ao som de sambas e marchinhas, em forma de cortejo, fantasiadas ou não, tendo uma bateria (conjunto de percussões) como base rítmica (PIMENTEL, 2003). Mas a própria organicidade do carnaval carioca vem demonstrando sua mutabilidade a cada ano. Se no primeiro período da chamada retomada do carnaval de ruaXII, a partir de 1984, temos um conjunto de blocos com características um pouco mais homogêneas, a partir dos anos 2000, com a chegada do Monobloco e outros que vão apostar em novos ritmos, vamos encontrar variações de formas e novas expressões que não param mais a partir daí.

Atualmente, o Rio de Janeiro vive uma espécie de explosão do seu Carnaval de rua, à semelhança das primeiras décadas do século passado, a cidade é invadida por agrupamentos de foliões organizados das mais variadas formas. Chamados indiscriminadamente de bandas ou blocos, esses grupos podem desfilar cantando um único samba composto especialmente a cada ano, ao som de marchinhas carnavalescas tradicionais ou de ritmos variados como maracatu, ciranda ou rock. O acompanhamento musical pode ser uma bateria, ao estilo das escolas de samba, uma bandinha "furiosa" ou uma mistura de vários instrumentos (BEI, 2007, p. 7).

Os blocos do período de 1984 a 2000, fundados na Zona Sul da cidade, têm algumas características em comum, como a sátira política e a crítica social.
Desfilam como cortejos e nascem com alguns elementos oriundos da formação musical dos ranchos e das escolas de samba, como usar apenas um samba, autoral e temático, que muda de ano para ano, e que é disputado em concorridas festas para a escolhas do samba do ano em questão. Além disso, contam com baterias semeIhantes às das escolas, com os mesmos instrumentos e sob o comando de um ou mais mestres de bateria. Todos os blocos deste período desfilam com baterias, como é o caso do Simpatia É Quase Amor, até hoje sob o comando de Mestre Penha, formado no bloco de enredo Canarinhos das Laranjeiras, e do Imprensa Que Eu Gamo, que em seu primeiro desfile saiu com a bateria da Mangueira e manteve por muitos anos a bateria da São Clemente.

Outra característica desse conjunto de blocos da retomada é o uso de camisetas autorais, com charges ou desenhos de artistas plásticos, como uma marca de autenticidade. Não significam um "passaporte" de entrada ao bloco, como os abadás da Bahia, por exemplo, pois o carnaval do Rio não comporta nenhum tipo de restrição de entrada, áreas exclusivas e vips. As camisetas funcionam como elemento de pertencimento, item de identidade para quem quer ser "Suvaco", "Simpatia", "Barbas", e por aí vai. Usar a camiseta de um desses blocos é uma espécie de passaporte, uma forma de ser reconhecido como parte do grupo.

Essa configuração vai mudar com a chegada do Monobloco e de vários outros blocos que nasceram das escolas de percussão ${ }^{\mathrm{XIII}}$, que surgem na primeira década dos anos 2000. Uma nova geração de instrumentistas começa a ser formada na cidade, seduzida pela possibilidade de integrar as baterias dos grandes blocos na época do carnaval, e, ao mesmo tempo, pela possibilidade de novos encontros que as aulas propiciam. O tamborim é o instrumento mais procurado, adotado por uma maioria de mulheres que encontram seu 
espaço nas baterias, originalmente masculinas. A música tocada nos desfiles deixa de ser apenas uma, e os blocos adotam de tudo um pouco, adaptando ritmos e compositores para a batida do samba: entra o pop, o rock, o funk, o xote, o hip hop e outros nunca pensados no ritual do carnaval.

$\mathrm{Na}$ sequência aos blocos de percussão, surgem os blocos temáticos, iniciados com a experiência do bloco Exalta Rei, formado por um grupo de músicos que explora as canções do "Rei" Roberto Carlos. Seu primeiro desfile se dá em 2009, na Urca, e, a partir daí alguns grupos carnavalescos adotam a brincadeira de celebrar ou um cantor (Toca Raulll!!!!), um grupo musical (Sargento Pimenta), um tipo de ritmo (Chora Me Liga, Fogo e Paixão), um tema (Zoo Bloco, Super Mario Bloco, Desliga da Justiça). Dos blocos temáticos, chegamos ao neofanfarrismo, que é o movimento das novas fanfarras, não no modelo tradicional das fanfarras militares, apesar de usarem os mesmos instrumentos. São grupos musicais com uma "pegada" mais política", como se auto definem. Diferente de todos os anteriores, não usam carros de som, tendo como base um grupo musical instrumental de sopros e não mais com a prevalência das percussões. Fazem parte desse grupo agremiações como Orquestra Voadora, Dama de Ferro, Siderais, Virtual, Sinfônica Ambulante, entre outros atuais. Sobre as fanfarras:

O neofanfarrismo foi uma ideia que a gente começou a usar depois, já no final de 2008. Fui um dos que abraçou logo este rótulo. Tem um babado político nesta ideia [...]. A gente defendia a ideia de que é "neo" porque somos diferentes politicamente das fanfarras tradicionais, fanfarras militares e de pracinhas de cidades do interior. Não é só uma reformatação das fanfarras, mas um posicionamento mais crítico perante o mundo. (HERSCHMANN; FERNANDES, 2014, p. 35)
Diante de tamanha diversidade, interesses, intercâmbios, não há como homogeneizar o Carnaval de rua do Rio dentro de qualquer uma das classificações de cultura popular apresentadas na primeira parte deste artigo. Sabemos que é arte feita pelo povo, espontaneamente. Mas de qual povo estamos falando? Não se pode definir o Carnaval dos blocos por classes sociais, como se fosse uma manifestação fixa e apenas de um extrato. Nunca foi, basta um retrospecto na própria história do Carnaval para ver o quanto as classes foram se misturando e se alternando ao longo das diversas manifestações, como as sociedades carnavalescas, os cordões, os ranchos, as escolas de samba, a partir de meados do século 19. Tampouco podemos falar em tradição e preservação, pois é fato que o carnaval muda e se renova continuamente. Marta Abreu ressalta em seu texto que "o popular não é monopólio dos populares", que "o popular não se concentra em objetos. O importante são as mudanças de significados resultantes de interações" e ainda que "o popular não é vivido pelos agentes sociais como manutenção melancólica das tradições".

Por isso, os argumentos de Canclini sobre hibridismos parecem ser apropriados para trabalhar conceituações em relação a esse Carnaval, no século 21, longe das oposições entre tradicional e moderno, local e nacional, entre outras que já não servem. Eis alguns exemplos, como o do bloco Sargento Pimenta, que toca a música dos Beatles em suas apresentações. O bloco não desfila em cortejo, contrariando formações originais dos blocos de rua, e se apresenta em palco fixo no Aterro do Flamengo, para mais de 180 mil pessoas, segundo dados da Polícia Militar. Também não há nenhum elemento de tradição no Sargento Pimenta, se levarmos ao pé da letra algumas ideias como as defendidas pelo produtor cultural e compositor de blocos Lefê Almeida, de que Carnaval seria uma manifestação cultural ligada ao samba, em artigo publicado 
no jornal O Globo XIV. Como diz Canclini, nada é puro, as culturas são híbridas, e assim parece ser o que acontece por aqui. Por hibridismo, Canclini define os processos socioculturais nos quais estruturas ou práticas discretas, que existiam de forma separada, se combinam para gerar novas estruturas, objetos e práticas. É preciso desconstruir a divisão entre o culto, o popular e a cultura de massa.

Outro exemplo é o bloco "Feitiço do Villa", formado por músicos de orquestra, que em um desfile celebrou a música clássica comemorando Heitor Villa-Lobos. Saiu uma única vez, em 5 de março de 2011 (Dia Nacional da Música Clássica), naquele ano um sábado de Carnaval. Era formado por músicos eruditos que decidiram fazer arte popular, como definem em suas páginas nas redes sociais:

Somos um grupo de músicos, produtores e empreendedores culturais que amamos a música clássica e também gostamos de carnaval (ou vice-versa). Decidimos organizar o bloco Feitiço do Villa porque, em 2011, o 5 de março, Dia Nacional da Música Clássica, caía um sábado de carnaval. Fazem parte da diretoria do bloco o maestro Carlos Prazeres; os músicos Edu Krieger, Marcelo Caldi e Roberto Rutigliano; os empreendedores culturais Heloisa Fischer e Luiz Alfredo Moraes, de VivaMúsica!; as produtoras Ana Paula Emerich e Cecília Valle.

Canclini cita alguns exemplos para "hibridação":

Algo frequente como a fusão de melodias étnicas com música clássica [...]; as reelaborações de melodias inglesas e hindus efetuadas pelos Beatles, Peter Gabriel e outros músicos". E acentua que o mais importante é o processo em si, e não o resultado. Vejo tanto de sua teoria no que acontece hoje em dia com os quase 600 blocos da cidade, que convivem por cerca de dois meses em múltiplas manifestações culturais intituladas de forma homogênea "carnaval de rua", sendo que as características entre elas são totalmente distintas e nem sempre convergentes. É como diz o sociólogo, "frequentemente a hibridação surge da criatividade individual e coletiva [...]. Busca-se reconverter um patrimônio [...] para reinseri-lo em novas condições de produção e mercado (CANCLINI, 2013, p. XX).

A hibridação interessa tanto aos setores hegemônicos quanto aos populares, que querem apropriar-se dos benefícios da modernidade. "Esses processos incessantes, variados, de hibridação, levam a relativizar a noção de identidade"Xv. Assim, a antiga abordagem de carnaval como identidade nacional poderia ser deslocada para o da heterogeneidade e de hibridação, como propõe Canclini. O estudo dos processos culturais, e nesse caso o Carnaval de rua do Rio, mais do que nos leva a afirmar uma identidade, nos leva a pensar a heterogeneidade das culturas populares, sua função de mutação e os ajustes sociais que se produzem ao longo do tempo, como condição de sobrevida da própria cultura, a exemplo da criativa ocupação dos territórios como são as ruas do Rio de Janeiro. São novos tempos que ainda precisam ser investigados. Tudo muito novo, mutante, mas sem dúvida, popular.

\section{Bibliografia}

ABREU, M. Cultura Popular: um conceito e várias histórias. In: ABREU, M; SOIHET, R. (org.). Ensino de história: conceitos, temáticas e metodologia. Rio de Janeiro: Casa da Palavra, 2003. p. 83.-102.

BEl. Guia do Carnaval de Rua do Rio de Janeiro. Rio de Janeiro: BEI Comunicação, 2007. 
BOURDIEU, Pierre. Você disse popular? Revista Brasileira de Educação, n. 1, jan/fev/mar/abr 1996. p. 16-26.

BURKE, Peter. Cultura Popular na Idade Moderna. São Paulo: Companhia das Letras, 2010.

CANCLINI, N. Culturas Híbridas: Estratégias para entrar e sair da Modernidade. São Paulo: EdUSP, 2013.

FRYDBERG, Marina Bay. Ó Abre Alas: Cultura e Economia através da Festa dos Blocos de Carnaval de Rua na Cidade do Rio de Janeiro. Artigo publicado no $38^{\circ}$ Encontro Anual da Anpocs GT02 - Arte e Cultura nas Sociedades Contemporâneas.

HERSCHMANN, M. Apontamentos sobre o crescimento do Carnaval de rua no Rio de Janeiro no século 21. Intercom. São Paulo, v. 36, n. 2, jul/dez. 2013. p. 267-289.

HERSCHMANN, M.; FERNANDES, C. Música nas Ruas do Rio de Janeiro. 2014. Rio de Janeiro: Intercom [E-book / recurso eletrônico].

SOIHET, R. A Subversão pelo Riso: estudos do carnaval carioca da Belle Époque ao tempo de Vargas. Rio de Janeiro: Editora FGV, 1998.

\section{Recebido em 15/07/2016 Aprovado em 17/08/2016}

I Maria Rita Dias de Almeida Fernandes. Mestranda do Programa de Mestrado Profissional em História, Política e Bens Culturais, CPDOC/FGV, jornalista e economista. Brasil. Contato: ritafernande@gmail.com

II Dados da Riotur em seu balanço final de Carnaval, publicado pelo órgão em seu site e divulgado para toda a imprensa.

III Só existe um edital de fomento para o Carnaval - não apenas direcionado para os blocos, mas para todas as modalidades carnavalescas - lançado anualmente pela Secretaria Estadual de Cultura. Esse edital prevê o valor de R\$ 1 milhão para atender todas as manifestações carnavalescas do estado do Rio, incluindo-se aí os mais de 500 blocos de rua da capital.
IV Dirigentes de blocos e associações e ligas

$\checkmark$ Desliga dos Blocos do Rio é um grupo de blocos associados com um discurso de valorização da tradição, que defende a ocupação da cidade de forma espontânea, sem normas e legislações. Por isso, a maioria dos blocos associados a Desliga dos Blocos sai no carnaval sem pedir autorização para a prefeitura.

VI Informações disponíveis no Blog Acesso - http:// www.blogacesso.com.br/?p=5838 - acesso em 12 de julho de 2016.

VII A Sebastiana é a Associação Independente de Blocos da Zona Sul, Santa Teresa e Centro da Cidade de São Sebastião do Rio de Janeiro, a primeira que surgiu no período da retomada do carnaval de rua, em 2000. Realiza anualmente este seminário, desde 2003, para debater os desafios e as questões diretamente ligadas à festa, seu crescimento e sua relação com a cidade.

VIII A Riotur, órgão da Secretaria Municipal de Turismo, lançou um primeiro decreto exigindo que os organizadores dos blocos dessem entrada em pedidos de autorização de desfiles em fevereiro de 2009.

IX Informações em Blog Acesso - http://www.blogacesso.com. $b r / ? p=5838$ - acesso em 12 de Julho de 2016.

X CANCLINI, N. Culturas Híbridas: Estratégias para entrar e sair da Modernidade. São Paulo: EdUSP, 2013.

XI Rachel Soihet dedica seu livro a pesquisar a participação dos segmentos subalternos no Carnaval do Rio de Janeiro, de 1890 ao tempo de Vargas. Os conceitos de interpenetração e de circularidade cultural estão no centro de suas pesquisas, que analisam as formas de atuação dos chamados "subalternos" diante dos obstáculos com os quais têm que confrontar.

XII O que vem sendo chamado de retomada do carnaval de rua no Rio corresponde a dois períodos distintos, como explica Micael Herschmann em seu "Apontamentos sobre o crescimento do carnaval de rua": o primeiro, mais tímido, mas precursor, data de 1984 com a chegada de blocos como Barbas e Simpatia É Quase Amor na Zona Sul do Rio, depois de um longo período com pouca atividade do carnaval de rua. E o segundo, chamado de o boom do carnaval, o que começa na primeira década dos anos 2000, com uma explosão de agremiações por toda a cidade.

XIII Bangalafumenga, Empolga às 9, entre outros.

XIV Lefê Almeida. "O poder de resistência dos cariocas" publicado na editoria de Opinião do jornal O Globo em 15 de fevereiro de 2007.

XV CANCLINI, 2013: Introdução, p. XXIII . 